\title{
Reference values for lung function: past, present and future
}

\author{
S. Stanojevic*,\# A. Wade ${ }^{\#}$ and J. Stocks*
}

ABSTRACT: Reliable interpretation of pulmonary function results relies on the availability of appropriate reference data to help distinguish between health and disease and to assess the severity and nature of any functional impairment.

The overwhelming number of published reference equations, with at least 15 published for spirometry alone in the past 3 yrs, complicates the selection of an appropriate reference. The use of inappropriate reference equations and misinterpretation, even when potentially appropriate equations are used, can lead to serious errors in both under and over diagnosis, with its associated burden in terms of financial and human costs.

Further misdiagnosis occurs when fixed cut-offs, such as $80 \%$ predicted forced expiratory volume in $1 \mathrm{~s}\left(\mathrm{FEV}_{1}\right)$ or $0.70 \mathrm{FEV}_{1}$ /forced vital capacity, are used; particularly in young children and elderly adults. While per cent predicted has historically been used to interpret lung function results, z-scores are more appropriate as they take into account the predicted value, as well as the between-subject variability of measurements.

We aim to highlight some of the main issues in selecting and using reference equations and discuss how recent developments may improve interpretation of pulmonary function results.

\section{KEYWORDS: Normal values, pulmonary function testing, reference values, review, spirometry}

ike most medical observations, reliable interpretation of pulmonary function results relies on the availability and use of appropriate reference data to help distinguish between health and disease and to assess the severity and nature of any functional impairment. The overwhelming number of published reference equations, with at least 15 published for spirometry alone in the past 3 yrs, complicates the selection of an appropriate reference. The use of inappropriate reference equations and misinterpretation, even when potentially appropriate equations are used, can lead to serious errors in both under and over-diagnosis, with its associated burden in terms of financial and human costs [1, 2]. Furthermore, overdependence on fixed cut-offs to define abnormality, irrespective of well recognised age-related changes, further magnifies these problems [3-7].

In this article we aim to highlight some of the main issues in selecting and using reference equations and discuss how recent developments may improve interpretation of pulmonary function results. In the interests of brevity, this article has been limited to spirometric reference data, but most of the principles discussed apply to other pulmonary function tests. No attempt has been made to provide a comprehensive review of all available reference data, with emphasis instead being placed on what is commonly used, new developments in the past 3 yrs and practical issues relating to the use and misuse of reference data.

\section{WHAT IS NORMAL?}

The range of values obtained from a "healthy population" is assumed to represent normal. Individuals with values outside the central 95\% of this range (which may be defined as the normal range) are often considered to have atypical results and are referred for further testing. Unlike many other medical observations, lung function measurements are frequently related to body size and age, where height is a proxy for chest size, and age reflects maturity. During childhood and adolescence, growth is particularly rapid with lung function increasing 20 -fold during the first 10 yrs of life [8]. By contrast, once peak lung function has been attained during early adulthood, this peak being some 5 yrs later in males than females, there is a steady age-related decline in most lung function

\section{AFFILIATIONS}

*Portex Respiratory Unit, UCL Institute of Child Health, and \#MRC Centre of Epidemiology for Child Health, UCL Institute of Child Health, London, UK.

\section{CORRESPONDENCE}

S. Stanojevic

Portex Respiratory Physiology Unit UCL Institute of Child Health 30 Guilford Street

London

WC1N 1EH UK

E-mail: s.stanojevic@ich.ucl.ac.uk

Received:

Sept 102009

Accepted after revision:

Nov 242009 
outcomes $[9,10]$ (fig. 1). While the precise age at which lung growth ceases depends on whether cross-sectional or longitudinal data are inspected $[12,13]$, height, age, sex and, ideally, ethnic/racial group must be taken into consideration when defining the normal range for lung function.

The selection of "healthy" subjects who comprise the reference population is of paramount importance [14]. However "health" itself is difficult to define and the choice of appropriate inclusion and exclusion criteria often depends on the intended use of the reference ranges. Inevitably there will be differences between the predicted values derived from studies which have selected a sample from the general population (i.e. minimal exclusion criteria) compared to studies which have specifically excluded those with any clinical risk factors (for example, smoking history, pollutant exposure, history of respiratory symptoms). Ideally the sample should be unbiased and generalisable, with the characteristics of the reference population well documented so they can be considered by the user.

\section{POPULATION-SPECIFIC REFERENCE EQUATIONS}

The observed differences between reference equations may be explained by differences in population characteristics, although the equipment, software and measurement technique used may also explain some of the variation $[15,16]$. Therefore, steps should be taken to ensure that the reference equations selected by the user are applicable and appropriate for the population being tested. In practice this is extremely difficult to achieve as it ideally necessitates investigating a large number of healthy subjects of both sexes over the entire relevant age range from the local community, so that small but important differences may be identified [17]. In future, a consortium of users who are using the same equipment, software and methodology in similar populations may be able to address this issue more effectively. Manufacturers should help to coordinate such efforts and facilitate the decision-making process by providing an easy to search guide of the selected reference population together with details of equipment and measurement protocol used. These issues are currently being addressed by a European Respiratory Society (ERS) working group [17].

The available references may also lead us to question the necessity of population-specific equations or the more practical solution of large generalisable (multicentred) reference populations [14, 18]. Population-specific equations might be more representative of the population being tested but are expensive, logistically difficult and based on a smaller number of subjects than can be included in multicentre studies. By contrast, equations based on large representative populations may be less accurate but more precise. Recently published measurement and equipment standards in both young children and adults $[7,19,20]$ should help to make reference data more comparable across different populations and equipment types in future.

Neither of the two approaches deals adequately with the wellrecognised ethnic differences in lung function [16, 21, 22]. Defining ethnicity itself is both complex and continually evolving. The issue of how best to address the impact of variation in ethnicity when interpreting lung function tests requires urgent international attention. Ideally, multi-ethnic populations should be studied using identical equipment and protocols and a more sophisticated approach to characterising body shape and size, with modern statistical techniques [23] applied to the resultant data. This would enable the effect of population characteristics to be distinguished from those of methodology and may show that appropriate anthropometric adjustments will allow one set of equations to be applied across a wide range of ethnic groups.

\section{WHAT IS RECOMMENDED?}

Currently, the American Thoracic Society (ATS) recommend the use of the third National Health and Nutrition Examination Survey (NHANES III) reference [21] for interpreting spirometry results. This dataset is one of the few references spanning childhood and adulthood, which is also nationally representative and generalisable. The ERS does not recommend a particular reference, although in Europe the European
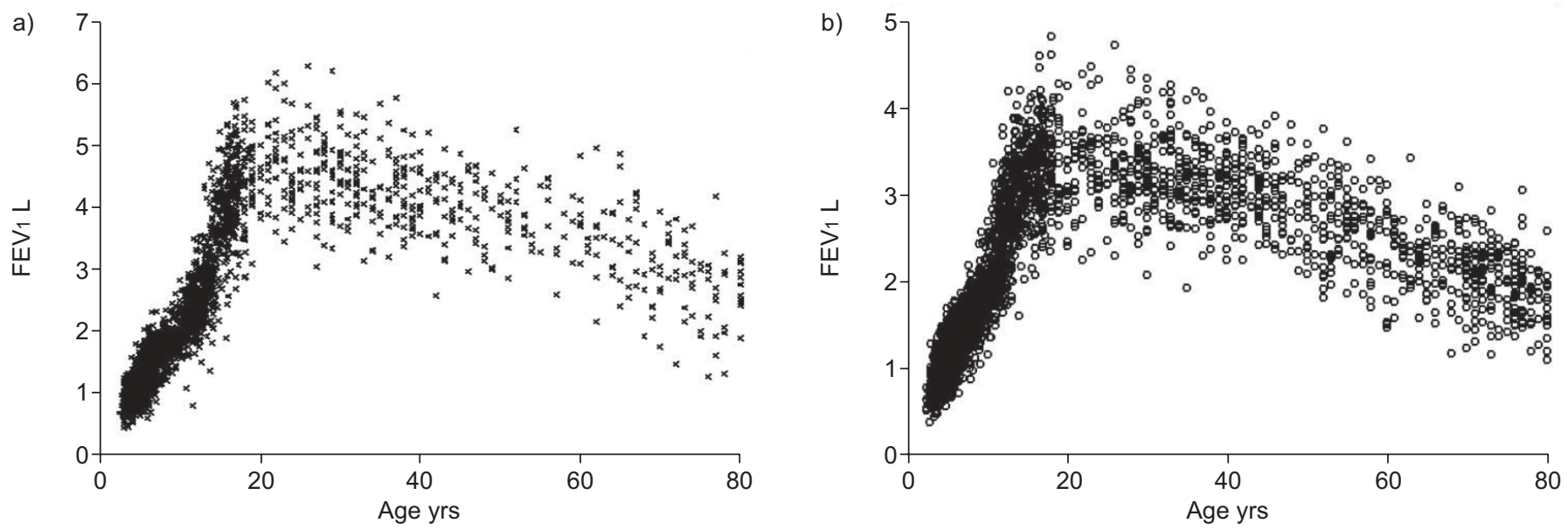

FIGURE 1. The nonlinear relationship between age and forced expiratory volume in $1 \mathrm{~s}(\mathrm{FEV} 1)$ in a) males and b) females. Data obtained from Caucasian subjects in [8] 
Community for Steel and Coal reference [24] is most widely used. In the UK, it is recommended that the reference equation of Rosenthal et al. [25] be used in children aged $<18$ yrs, whereas the European Community for Steel and Coal equations are usually adopted in adults. Australia, New Zealand and the Asia-Pacific region do not set recommendations but leave it to individual laboratories to select appropriate reference equations. Even when recommendations are available, problems may arise if laboratories do not adhere to the same quality standards and equipment (or even software) when measuring patients in clinical settings compared to those used to construct the reference ranges.

The ATS and ERS both recommend the use of the lower limit of normal (LLN), or upper limit where appropriate (i.e. plethysmographic lung volumes), to delineate between health and suspected disease. As, by convention, the LLN is set at $5 \%$, whereby $90 \%$ of the healthy population fall within the normal range, it must be appreciated that using this cut-off results in a $5 \%$ false positive rate.

\section{WHAT IS COMMONLY USED?}

Despite the profound influence that the choice of reference equation may have on the interpretation of results [1, 2], many users of lung function equipment, and indeed the clinicians who request such tests, are not aware of which equations are being used to interpret results, simply relying on default values set by manufacturers at the time of installation. Although it is now recognised that the source of reference data should be an integral component of any pulmonary function test report, this practice has yet to be implemented by many manufacturers and users.

To ascertain which reference equations are currently available in commonly used equipment and how these equations are used and presented to the user, we surveyed manufacturers of spirometry equipment. From the results of 16 companies who responded it was evident that, despite the growing number of published reference equations, relatively few are readily available in equipment software. The majority of systems have the facility to install new equations upon request and to switch between adult/paediatric or Caucasian/non-Caucasian equations, but relatively few provide guidance to assist the respiratory scientist to select the most appropriate population group according to age or ethnic group of the subject being studied.

It is also apparent that the default equations set by several manufacturers are still based on reference equations that were developed more than 30-40 yrs ago. The development of international standards over the past two decades [7, 20], with corresponding changes in equipment, software and measurement techniques, combined with shifts in population characteristics, means that such equations may no longer be appropriate.

Another major limitation remains the lack of a single reference across all ages. The NHANES III reference is limited by a lack of subjects aged $<8$ yrs and $>80$ yrs, which often results in reference data being extrapolated to younger and older ages. SUBBARAO et al. [2] have demonstrated the inaccuracies in interpreting results at younger ages using NHANES III, and the ATS and ERS strongly discourage extrapolation of reference data beyond the intended age/height range [16].
The alternative, to use paediatric reference equations before switching to NHANES III, as currently recommended by the CF Foundation (M. Rosenfeld, CF Foundation, Bethesda, MA, USA; personal communication), introduces discontinuities between equations at the transition point (fig. 2). These arbitrary jumps mean that interpretation of results may not reflect either baseline or change in clinical status of the subject, particularly at crucial junctions of clinical care, such as between paediatric and adult centres.

\section{WHAT IS NEW?}

The continued publication of new reference equations reflects the widespread recognition of the limitations of existing equations, particularly with respect to specific ethnic groups. In the past 3 yrs reference equations have been published for: Brazilian adults [27], Polish adults [28], Chinese adults [29], Kazakh adolescents [30], Italian adults [31], and young children $[32,33]$. However, the abundance of unrelated studies can introduce new complexities, not least because most are not generalisable to any other population than the one in which they were collected. Two exceptions to this were the Health Survey for England [32], which studied a large population (6,053 individuals) and included subjects from 16-90 yrs [31], and the recently published study by KUSTER et al. [35] which was also based on a very large sample $(8,684$ individuals aged $18-80 \mathrm{yrs})$ and used sophisticated statistical techniques to define a more accurate, age-dependent, LLN. While both of these populations were representative for those of English and Central European origins across a wide age range, they are limited by a lack of data in non-Caucasians and younger children aged $<16$ yrs. Furthermore, KUSTER et al. [35] used self-reported height, which may introduce errors in the

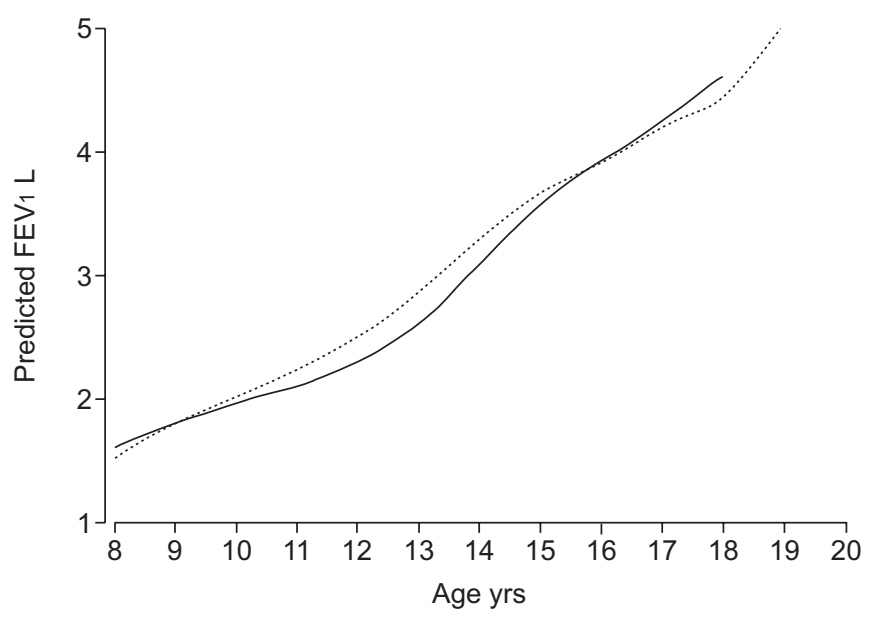

FIGURE 2. Comparison between prediction equations from WANG et al. [26] $(-)$ and HankINSON et al. [21] $(\cdots \cdots \cdots)$ in males during childhood. At the stage at which the Cystic Fibrosis Foundation recommends switching between WANG et al. [26] and HANKINSON et al. [21] (17 yrs and 15 yrs in males and females, respectively), there is a difference in predicted forced expiratory volume in $1 \mathrm{~s}(\mathrm{FEV} 1)$ of $\sim 1 \%$ in males and $2 \%$ in females (data not shown); however, the individual change can be up to $8 \%$ predicted. Reproduced with permission from the CF Foundation Registry Committee Task Force on Reference Equations (www.cff.org). 
predicted values as well as bias, particularly in elderly subjects who tend to overestimate their current height. Both of these studies were limited to older subjects, thereby excluding the complexities of puberty and growth spurts. The Italian equations by PISTELLI et al. [31] do attempt to develop smoothly changing equations across the entire age range but are limited to $<500$ subjects (aged $8-74$ yrs) from one population and, therefore, may not be representative.

\section{PRE-SCHOOL EQUATIONS}

Although several paediatric reference equations have been published, very few include children aged $<5$ yrs, measurement guidelines for which were only published recently [20]. Of the pre-school equations that are available, lack of details regarding either the population characteristics or measurement techniques, together with a failure to link results to school-age equations, may limit their usefulness beyond the centre where they were generated [36]. Furthermore, many are based on forced expiratory volume in $1 \mathrm{~s}$ (FEV1), which may not be an appropriate measurement for very young children. These factors, together with the extent to which equations have been extrapolated beyond the intended height and age range, mean that paediatric spirometry results are frequently subject to misinterpretation

In 2007, two specific studies for children aged $<6$ yrs were published $[32,33]$. Both included reference equations for FEV in $0.75 \mathrm{~s}$ (FEV0.75). This may be a more appropriate outcome for this age group, since young children have large airways relative to their lung volumes such that, during forced expiration, emptying may be virtually complete within $1 \mathrm{~s}$, if not earlier [8].

\section{STATISTICAL MODELLING}

The complex nature of the relationship between body size and lung function, particularly during periods of rapid growth [37-39] means that traditional and commonly used multiple regression analysis is not sufficient. Recent advances in computational power and statistical software allow more sophisticated statistical methods to be applied relatively easily [40]. This added flexibility allows the complexity of the relationship to be quantified to reflect biologically plausible relationships of lung function with age and height using a smoothly changing model.

\section{ALL AGE EQUATIONS}

Given the well-recognised issues around the use and misuse of reference equations, two recent international collaborative initiatives have attempted to address some of the described limitations. The "all-age spirometry" study [41] investigated ways to develop more appropriate reference ranges which could describe the relationship between lung function, height and age more accurately during childhood, while also being applicable to adults and the critical transition between the two (fig. 3). These equations provide smoothly changing reference curves during periods of rapid growth and transition to produce a single reference across a wide age range (5-80 yrs) in Caucasians. Furthermore, the equations describe a multiplicative and allometric relationship, where FEV1, forced vital capacity (FVC) and forced expiratory flow at $25-75 \%$ of FVC (FEF25-75) are proportional to height raised to the power 2.5.
For example, a $1 \%$ increase in height corresponds to a $2.5 \%$ increase in spirometry.

Since publication in 2008, these data have been supplemented with the largest collection of pre-school data (3-7 yrs) to extend the continuous all-age models from 3-80 yrs without changing the equations in children aged $>10$ yrs [8]. In addition to extending the outcomes already reported, reference equations were developed for FEV0.75.

The all-age reference demonstrates that the between-subject variability in lung function is highly age-dependent, which has important implications for defining the LLN. The largest degree of variability was observed in children aged $<11$ yrs, but between-subject variability also increased steadily with age after 30 yrs (fig. 4). The practical implication of these findings is that the "normal range" for FVC or FEV1 is considerably wider than the frequently quoted $80-120 \%$ pred both for young children and for subjects aged $>30$ yrs. Table 1 demonstrates several examples of the predicted values across the age range, along with the LLN (-1.645 z-scores) and the normal range using per cent predicted. This study also emphasised the much wider normal range for FEF25-75 compared with FEV1 and FVC.

\section{IMPLEMENTATION OF ALL-AGE EQUATIONS}

Due to the complexity of the smoothly changing models, the equations cannot be expressed as simple polynomial equations, instead they require look-up tables. Most modern pulmonary function test software can install the equations and complementary tables required. The equations are also available as an Excel add-in (fig. 5) and can be downloaded from www.growinglungs.org.uk [42].

\section{INTERPRETING RESULTS}

Clinicians in respiratory medicine have become familiar with the concept of expressing lung function as per cent predicted, (observed/predicted) $\times 100$, where the predicted value is derived from reference equations. The median predicted value is $100 \%$ and any deviation from $100 \%$ indicates an offset from the predicted value. Conventionally, the variability between healthy subjects is taken to be an SD of $10 \%$. On this basis, the normal predicted range would be from $80 \%$ to $120 \%$.

This may be valid so long as the between-subject SD genuinely is $10 \%$ at all ages and for all lung function outcomes. In practice it is not (fig. 4). The flexible modelling techniques used when developing the all-age equations have quantified the SD and demonstrated that it is highly age and outcome dependent [8, 41]. In young children and the elderly, for example, the SD for FEV1 is close to $15 \%$, so that the normal range extends from $70 \%$ to $130 \%$, and is $67-133 \%$ for $3 \mathrm{yr}$-olds (table 1). Ignoring this age-dependent variability means many patients will be flagged incorrectly as "abnormal". Furthermore, the variability is appreciably greater for flows (FEF25-75) than for volumes, the "normal range" being between 46-154\% in a 3 yr-old.

A better approach to reporting lung function measures is to express results as z-scores (or SD scores). The z-score is a mathematical combination of the per cent predicted and the between-subject variability to give a single number that accounts for age- and height-related lung function variability 


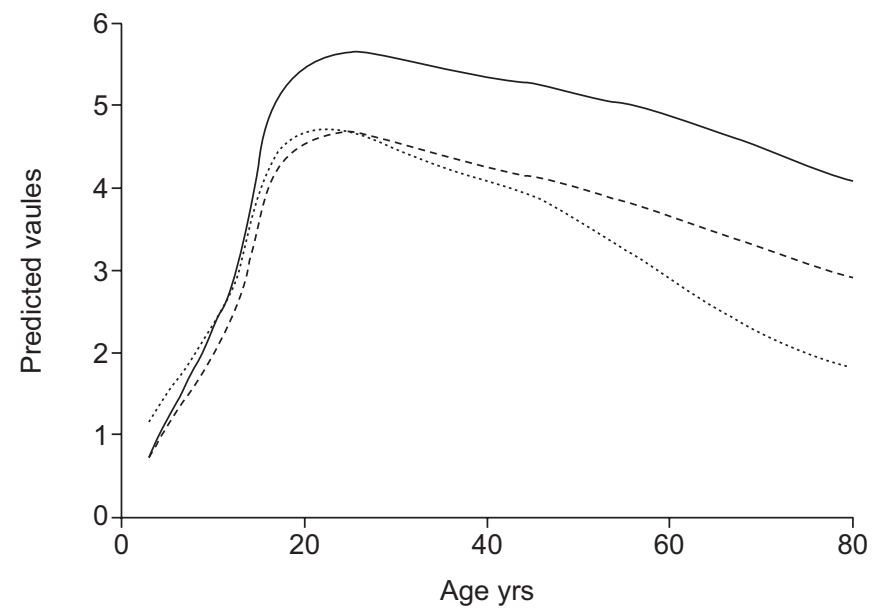

FIGURE 3. Predicted median for forced expiratory volume in $1 \mathrm{~s}$ in $\mathrm{L}(-\ldots-)$, forced vital capacity (FVC) in L (-) and forced expiratory flow at $25-75 \%$ of FVC in $L \cdot S^{-1}(\cdots \cdots \cdots)$.

expected within comparable healthy individuals. The LLN for a z-score is a value of -1.64 . Unlike per cent predicted, where each outcome has a different cut-off, the same cut-off of -1.64 for z-scores applies across all ages, sex, ethnic groups and spirometric pulmonary function indices. For example, in a $160 \mathrm{~cm}$ tall, 50-yr-old male, an FEF25-75 of 60\% pred and an FEV1 of $80 \%$ pred both equate to a $\mathrm{z}$-score of -1.5 . For some lung function outcomes (e.g. plethysmographic lung volumes), impairment is indicated by an elevated value, in which case an upper limit of normal or $95 \%$ percentile (z-score 1.64) would be used. There are still many questions to be answered before a consensus can be reached regarding what requirements an index of severity of lung disease should fulfil. We may need to adopt an entirely different approach in future to ascertain, for example, what is the minimum FEV1 required to sustain life and what is the level (whether in a "pathological" range or not) which does not limit our daily activities. Furthermore, a lung function test must never be used in isolation to define disease severity; a number of factors including quality of life are likely to contribute, and the ideal approach remains to be determined. Neither per cent predicted nor z-scores used in isolation can answer those fundamental questions.

Regardless of whether z-scores or per cent predicted are used to express results, the age-specific normal range should always be included in the lung function report. When interpreting results, it is important to remember that there will always be a degree of within-person variability, so that by chance a measurement may be just outside the "normal range" on one occasion, but just within it on the next. It is also essential to take other clinical information into account, and to weigh the consequences of an erroneous decision against that of a correct diagnosis. Particular caution is required when interpreting results which lie close to the somewhat arbitrary cut-offs between health and suspected disease, especially when results are limited to a single test occasion. Presentation of the actual z-score rather than whether it lies above or below some cut-off will assist interpretation.

\section{FEV 1 /FVC RATIO}

The limitations of using a fixed ratio as a cut-off to define airway obstruction have also been highlighted recently.

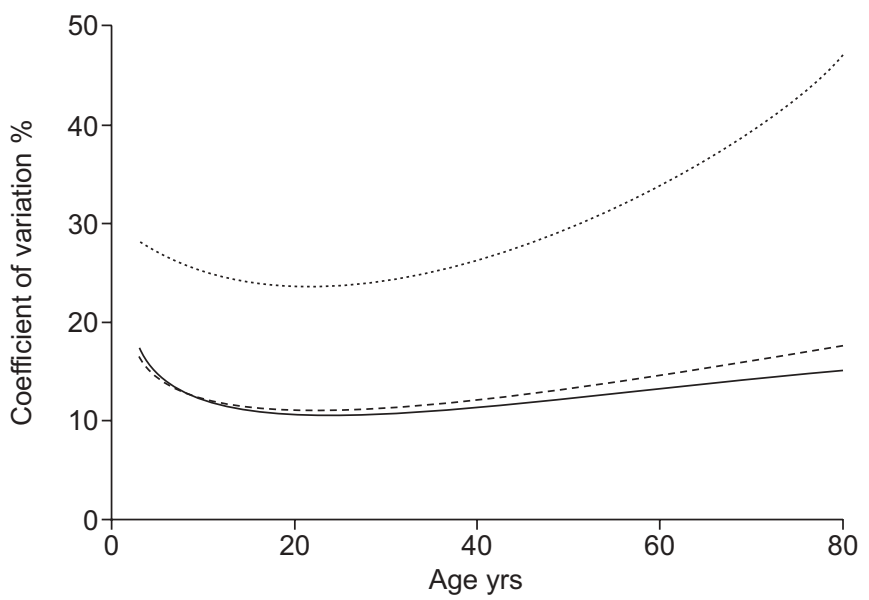

FIGURE 4. Between-subject variability in males measured by the coefficient of variation (CV). The CV is defined as $100 \times(\mathrm{SD} /$ median). When the CV is $10 \%$ (as is the case for forced expiratory volume in $1 \mathrm{~s}$ (FEV1) and forced vital capacity (FVC) in young adults) the normal range on either side of $100 \%$ predicted is $80-120 \%$ pred. By contrast, in younger and older subjects, the lower limit of normal for FEV1 will drop to $70 \%$ predicted when CV is $15 \%$, whereas that for forced expiratory flow at 25-75\% of FVC (FEF25-75) may be 40\% (CV of 30\%) or lower. ——: FVC males; - - - - : FEV1 males; $\cdots \cdots \cdot$ : FEF25-75 males.

HANSEN et al. [43] found the use of the Global Initiative for Obstructive Lung Disease criteria $(<0.7$ FEV1/FVC and FEV1 below the normal range) resulted in an inappropriately high prevalence of obstruction in adults aged $>70$ yrs. The all-age spirometry analysis indicated the ratio has a strong negative age dependency, the frequently used fixed threshold of 0.7 for FEV1/FVC not being attained until $\sim 50$ yrs of age in males and later in females, such that airway obstruction in younger subjects would be missed. By contrast, the use of the 0.7 cut-off would falsely identify a large number of older healthy subjects as having lung disease. Similar observations were made when data from 40,646 adults aged 17-90 yrs were re-examined [4].

\section{OUTSTANDING ISSUES Elderly subjects}

There is a relative lack of reference data for elderly subjects [35], with existing data based on relatively small and unrepresentative samples. Most of the currently recommended reference equations were developed in the 1980s and 1990s such that the older participants would be those born at the beginning of the 20th Century, with potential for cohort effects due to changes in health, nutrition and measurement standards [44]. The tendency for over-estimated, self-reported height in the elderly may add further bias. Recent studies, such as those by FALASCHETTI et al. [34] and KUSTER et al. [35], are particularly important as they can provide more appropriate reference equations for current generations. As lung function is highly age dependent in adults, future studies should aim to include a larger number of older subjects to improve the accuracy with which we can interpret spirometry in this population.

\section{Ethnicity}

Despite recent progress, there remains a lack of appropriate equations for ethnic groups other than those of white European 


\begin{tabular}{|c|c|c|c|c|c|}
\hline TABLE 1 & \multicolumn{5}{|c|}{$\begin{array}{l}\text { Examples of predicted values in males and } \\
\text { females across the age range studied }\end{array}$} \\
\hline Age yrs & Height $\mathbf{c m}$ & Sex & $\begin{array}{l}\text { Predicted } \\
\text { FEV1 L }\end{array}$ & FEV1 LLN L & $\begin{array}{c}\text { FEV } 1 \text { LLN } \\
\% \text { pred }\end{array}$ \\
\hline 3 & 99 & Male & 0.79 & 0.58 & 73.4 \\
\hline 5 & 115 & Female & 1.17 & 0.89 & 76.1 \\
\hline 7 & 122 & Male & 1.45 & 1.14 & 78.6 \\
\hline 11 & 133 & Male & 1.80 & 1.45 & 80.6 \\
\hline 15 & 150 & Male & 2.71 & 2.20 & 81.2 \\
\hline 20 & 159 & Female & 3.12 & 2.52 & 80.8 \\
\hline 25 & 170 & Female & 3.61 & 2.92 & 80.9 \\
\hline 30 & 186 & Female & 4.32 & 3.49 & 80.8 \\
\hline 40 & 162 & Male & 3.38 & 2.71 & 80.2 \\
\hline 50 & 175 & Male & 3.79 & 2.97 & 78.4 \\
\hline 60 & 183 & Male & 3.85 & 2.93 & 76.1 \\
\hline 70 & 172 & Female & 2.52 & 1.92 & 76.2 \\
\hline 80 & 169 & Male & 2.55 & 1.81 & 71.0 \\
\hline
\end{tabular}

These data are presented as an example and should not be used to define abnormal results in individual patients. FEV1: forced expiratory volume in $1 \mathrm{~s}$; LLN: lower limit of normal.

descent, especially among younger children. In the past, even when attempts to correct for such ethnic differences have been made, these have tended to apply the same fixed adjustment factor across all ages, all ethnic groups, both sexes and all spirometric outcome measures, an approach now shown to be over-simplistic [22, 41].

Ethnic-specific equations are not necessarily a satisfactory solution since this approach requires large and representative samples, which are not readily available. Currently, most ethnic-specific equations are based on small numbers, which are unlikely to be either representative or generalisable. Most importantly, ethnicity itself is extremely difficult to define, especially given the growing multi-ethnic population, and may be politically sensitive with some nations now forbidding recording of such details. Therefore, there is an urgent need for future research in this field to focus on finding an appropriate proxy measure, which accounts for the variability in lung function due to ethnicity. While sitting height has been suggested as an appropriate measure, it may not be practical to measure in clinical settings. Furthermore, sitting height was not found to explain the variability observed in Asian subjects [22] and may not be appropriate for all ethnic groups.

\section{Tracking longitudinal changes}

Accurate identification and interpretation of changes in lung function as a result of disease or treatment requires knowledge of normal variability over time within healthy subjects [45-47], but most reference ranges are based on cross-sectional samples with a paucity of data regarding either short- or long-term repeatability of spirometry [44]. Spirometry is an effortdependent technique, the accuracy and repeatability of which depends on many factors including the equipment used, coordination and motivation of the subject, skill of the technician and overall quality control. Thus, studies that include repeated measures in health over specified time

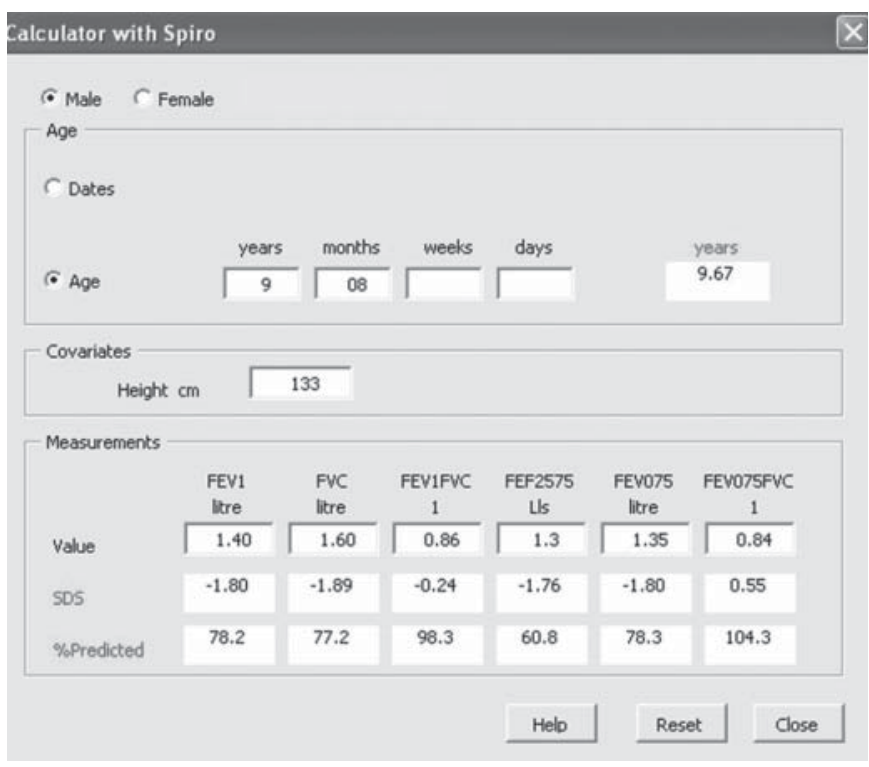

FIGURE 5. Screen-shot from Spiro.xls (www.growinglungs.org.uk [42]) in LMSgrowth demonstrating how an individual's sex, age, height and spirometry results can be entered to obtain z-scores (standard deviation scores; SDS) or \% predicted. The same method can be applied for an entire dataset by using the measurement SDS function to retrospectively analyse data.

intervals (ranging from within day, to over a week, month or year) are urgently required, this being particularly pertinent during periods of rapid growth and development.

\section{Future steps}

Many important advances have occurred in recent years including: 1) the development of standardised measurement protocols across all ages, including those for pre-school children [7, 19, 20]; 2) application of more appropriate statistical techniques for developing reference equations [31, $35,41]$; and 3) the establishment of collaborative networks with access to spirometry and other pulmonary function testing data in healthy individuals [17]. Such initiatives provide an opportunity to develop an international collaborative group that can take the next steps towards developing more up-todate and generalisable reference equations applicable across different populations and equipment models. A large multinational collaborative study also has the potential to address the lack of ethnic-specific equations or to develop more appropriate adjustment factors. An initiative such as this has the potential to be expanded to other pulmonary function tests. The established collaborative initiatives could eventually be extended to include infants, elderly subjects and different ethnic groups in order to track the longitudinal development throughout the life course. Such references would of course need maintenance and update (every 5-10 yrs) and, as such, would need allocation of long-term funding.

Finally, these advances will have little impact unless disseminated and implemented in equipment software. Both manufacturers and users need to ensure the most appropriate reference is applied. As an initial step forward, manufacturers should clearly display the source of the reference equations and assist the technician to select equations based on the most 
appropriate population group, according to age and ethnic background. To facilitate interpretation of results, manufacturers should also ensure that z-scores and the lower and upper limits of normal are also clearly displayed, ideally with a bar delineating the position of the actual data relative to the predicted mean and normal range.

\section{SUPPORT STATEMENT}

S. Stanojevic received funding from Asthma UK (London, UK).

\section{STATEMENT OF INTEREST}

None declared.

\section{ACKNOWLEDGEMENTS}

We gratefully acknowledge the assistance of T. Cole and P. Quanjer with respect to much of the work underpinning this report. We also thank H. Pan for developing the lmsGrowth macro and the spirometry add-in.

\section{REFERENCES}

1 Rosenfeld M, Pepe MS, Longton G, et al. Effect of choice of reference equation on analysis of pulmonary function in cystic fibrosis patients. Pediatr Pulmonol 2001; 31: 227-237.

2 Subbarao $\mathrm{P}$, Lebecque $\mathrm{P}$, Corey $\mathrm{M}$, et al. Comparison of spirometric reference values. Pediatr Pulmonol 2004; 37: 515-522.

3 Crapo RO. The role of reference values in interpreting lung function tests. Eur Respir J 2004; 24: 341-342.

4 Swanney MP, Ruppel G, Enright PL, et al. Using the lower limit of normal for the FEV1/FVC ratio reduces the misclassification of airway obstruction. Thorax 2008; 63: 1046-1051.

5 Miller MR, Steenbruggen I, Quanjer PH, et al. Defining the lower limit of normal for FEV1/FVC. Am J Respir Crit Care Med 2007; 176: 101.

6 Quanjer PH, Schouten JP, Miller MR, et al. Avoiding bias in the annualized rate of change of FEV1. Am J Respir Crit Care Med 2007; 175: 291-292.

7 Miller MR, Hankinson J, Brusasco V, et al. Standardisation of spirometry. Eur Respir J 2005; 26: 319-338.

8 Stanojevic S, Wade A, Cole TJ, et al. Spirometry centile charts for young Caucasian children: the Asthma UK Collaborative Initiative. Am J Respir Crit Care Med 2009; 180: 547-552.

9 Becklake MR, White N. Sources of variation in spirometric measurements. Identifying the signal and dealing with noise. Occup Med 1993; 8: 241-264.

10 Hibbert M, Lannigan A, Raven J, et al. Gender differences in lung growth. Pediatr Pulmonol 1995; 19: 129-134.

11 van Pelt W, Borsboom GJ, Rijcken B, et al. Discrepancies between longitudinal and cross-sectional change in ventilatory function in 12 years of follow-up. Am J Respir Crit Care Med 1994; 149: 1218-1226.

12 Quanjer PH, Borsboom GJ, Kivastik J, et al. Cross-sectional and longitudinal spirometry in children and adolescents: interpretative strategies. Am J Respir Crit Care Med 2008; 178: 1262-1270.

13 Johannessen A, Omenaas ER, Eide GE, et al. Feasible and simple exclusion criteria for pulmonary reference populations. Thorax 2007; 62: 792-798.

14 Chinn S, Jarvis D, Svanes C, et al. Sources of variation in forced expiratory volume in one second and forced vital capacity. Eur Respir J 2006; 27: 767-773.

15 Orfei L, Strachan DP, Rudnicka AR, et al. Early influences on adult lung function in two national British cohorts. Arch Dis Child 2008; 93: 570-574

16 Pellegrino R, Viegi G, Brusasco V, et al. Interpretative strategies for lung function tests. Eur Respir J 2005; 26: 948-968.
17 Lung Function in Growth and Aging: a united worldwide approach. www.lungfunction.org.

18 Stanojevic S, Wade A, Cole TJ, et al. Population-specific reference equations? Eur Respir J 2007; 29: 215.

19 Miller MR, Crapo R, Hankinson J, et al. General considerations for lung function testing. Eur Respir J 2005; 26: 153-161.

20 Beydon N, Davis SD, Lombardi E, et al. An official American Thoracic Society/European Respiratory Society Statement: pulmonary function testing in preschool children. Am J Respir Crit Care Med 2007; 175: 1304-1345.

21 Hankinson JL, Odencrantz JR, Fedan KB. Spirometric reference values from a sample of the general U.S. population. Am J Respir Crit Care Med 1999; 159: 179-187.

22 Whitrow MJ, Harding S. Ethnic differences in adolescent lung function: anthropometric, socioeconomic, and psychosocial factors. Am J Respir Crit Care Med 2008; 177: 1262-1267.

23 Cole TJ, Stanojevic S, Stocks J, et al. Age- and size-related reference ranges: a case study of spirometry through childhood and adulthood. Stat Med 2009; 28: 880-898.

24 Quanjer PH, Tammeling GJ, Cotes JE, et al. Lung volumes and forced ventilatory flows. Report Working Party Standardization of Lung Function Tests. European Community for Steel and Coal. Official Statement of the European Respiratory Society. Eur Respir Suppl 1993; 6: Suppl. 16, 5s-40s.

25 Rosenthal M, Bain SH, Cramer D, et al. Lung function in white children aged 4 to 19 years: I - Spirometry. Thorax 1993; 48: 794-802.

26 Wang X, Dockery DW, Wypij D, et al. Pulmonary function between 6 and 18 years of age. Pediatr Pulmonol 1993; 15: 75-88.

27 Pereira CA, Sato T, Rodrigues SC. New reference values for forced spirometry in white adults in Brazil. J Bras Pneumol 2007; 33 397-406.

28 Ostrowski S, Grzywa-Celinska A, Mieczkowska J, et al. Pulmonary function between 40 and 80 years of age. J Physiol Pharmacol 2005; 56: Suppl. 4, 127-133.

29 Ip MS, Ko FW, Lau AC, et al. Updated spirometric reference values for adult Chinese in Hong Kong and implications on clinical utilization. Chest 2006; 129: 384-392.

30 Facchini F, Fiori G, Bedogni G, et al. Spirometric reference values for children and adolescents from Kazakhstan. Ann Hum Biol 2007; 34: 519-534.

31 Pistelli F, Bottai M, Carrozzi L, et al. Reference equations for spirometry from a general population sample in central Italy. Respir Med 2007; 101: 814-825.

32 Pesant C, Santschi M, Praud JP, et al. Spirometric pulmonary function in 3- to 5-year-old children. Pediatr Pulmonol 2007; 42: 263-271.

33 Piccioni P, Borraccino A, Forneris MP, et al. Reference values of forced expiratory volumes and pulmonary flows in 3-6 year children: a cross-sectional study. Respir Res 2007; 8: 14.

34 Falaschetti E, Laiho J, Primatesta P, et al. Prediction equations for normal and low lung function from the Health Survey for England. Eur Respir J 2004; 23: 456-463.

35 Kuster SP, Kuster D, Schindler C, et al. Reference equations for lung function screening of healthy never-smoking adults aged 1880 years. Eur Respir J 2008; 31: 860-868.

36 Stanojevic S, Wade A, Lum S, et al. Reference equations for pulmonary function tests in preschool children: a review. Pediatr Pulmonol 2007; 42: 962-972.

37 Chinn DJ, Cotes JE, Martin AJ. Modelling the lung function of Caucasians during adolescence as a basis for reference values. Ann Hum Biol 2006; 33: 64-77.

38 Quanjer PH, Borsboom GJ, Brunekreef B, et al. Spirometric reference values for white European children and adolescents: Polgar revisited. Pediatr Pulmonol 1995; 19: 135-142.

39 Quanjer PH, Stocks J, Polgar G, et al. Compilation of reference values for lung function measurements in children. 
Standardization of Lung Function Tests in Paediatrics. Eur Respir J 1989; 2: Suppl. 4, 184s-261s.

40 Cole TJ, Green PJ. Smoothing reference centile curves: the LMS method and penalized likelihood. Stat Med 1992; 11: 1305-1319.

41 Stanojevic S, Wade A, Stocks J, et al. Reference ranges for spirometry across all ages: a new approach. Am J Respir Crit Care Med 2008; 177: 253-260.

42 UCL Institute of Child Health. Growing lungs. Growth charts for lung function. www.growinglungs.org.uk.

43 Hansen JE, Sun XG, Wasserman K. Spirometric criteria for airway obstruction: use percentage of FEV1/FVC ratio below the fifth percentile, not $<70 \%$. Chest 2007; 131: 349-355.
$44 \mathrm{Xu}$ X, Laird N, Dockery DW, et al. Age, period, and cohort effects on pulmonary function in a 24-year longitudinal study. Am J Epidemiol 1995; 141: 554-566.

45 Hibbert ME, Hudson IL, Lanigan A, et al. Tracking of lung function in healthy children and adolescents. Pediatr Pulmonol 1990; 8: 172-177.

46 Hnizdo E, Yu L, Freyder L, et al. The precision of longitudinal lung function measurements: monitoring and interpretation. Occup Environ Med 2005; 62: 695-701.

47 Sherrill D, Holberg CJ, Lebowitz MD. Differential rates of lung growth as measured longitudinally by pulmonary function in children and adolescents. Pediatr Pulmonol 1990; 8: 145-154. 